NBSIR 75.744

\title{
Proposed Implementation for Development of User-Terminal Protocols for Computer Network Access
}

Albrecht J. Neumann

Systems and Software Division

Institute for Computer Sciences and Technology

National Bureau of Standards

Washington, D. C. 20234

July 1975

Final

Sponsored by:

The National Bureau of Standards

and

The National Science Foundation

Office of Science Information Service

Interagency Agreement NSF CA-68 
NBSIR 75-744

PROPOSED IMPLEMENTATION FOR DEVELOPMENT

OF USER-TERMINAL PROTOCOLS FOR COMPUTER

NETWORK ACCESS

Albrecht J. Neumann

Systems and Software Division

Institute for Computer Sciences and Technology

National Bureau of Standards

Washington, D. C. 20234

July 1975

Final

Sponsored by:

The National Bureau of Standards

and

The National Science Foundation

Office of Science Information Service

Interagency Agreement NSF CA-68

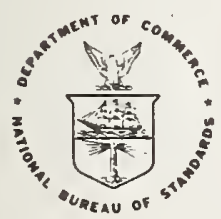

U.S. DEPARTMENT OF COMMERCE, Rogers C.B. Morton, Secretary

NATIONAL BUREAU OF STANDARDS, Ernest Ambler. Acting Director 

Th1s report is the final report to the National Science Foundation, under Interagency Agreement NSF CA-68, "Information Services Protocol." Under this grant a study was undertaken to provide the basis for possible standardization for user-terminal protocols. A workshop was held at NBS during October 1974, at which 35 invited authorities representing library and Information service users, software and service producers, and Federal agencies supporting major services were represented. Results of this workshop are reported in an NBS Technlcal Note ent1tled: A Basis for Standardization of User-Terminal Protocols for Computer Network Access. The Technical Note deals with the definition of protocols, and some of the requirements for message protocols, both to be entered by the user, and displayed to the user by the system.

The present report puts a proposed standardization effort into perspective by outlining related standardization efforts underway, by indicating some of the basic legal/requirements for standardization, by outlining objectives for a Federal standardization effort, and by indicating further research work required. The planned standardization effort will be sponsored by the National Bureau of Standards.

\section{ACKNOWLEDGMENT}

Constructive comments received from D. Fife, M. Keplinger, and $H$. White, helped to clarify the material presented, and their assistance is gratefully acknowledged. 
FOREWORD

ABSTRACT

1. Present Status of User-Terminal Protocol Standardization . . I

2. Related Standardization Activities . . . . . . . . 2

3. Federal Information Processing Standards . . . . . . 5

4. Constraints on the Standardization Process . . . . . . 6

5. Proposed Mechanism for Standards Development • • • • • 8

6. Further Research and Development Required . • . • . 10

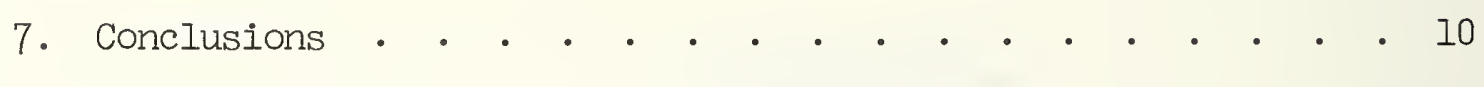

8. References . . . . . . . . . . . . . 12 
PROPOSED IMPLENENTATION FOR DEVELOPMENT OF USER-TERMINAL PROTOCOLS FOR COMPUTER NETWORK ACCESS

\author{
Albrecht J. Neumann
}

\title{
ABSTRACT
}

This report summarizes activities undertaken at the National Bureau of Standards in the area of User-Terminal Protocol Standardization with support from the National Science Foundation, during the latter part of 1974 and early 1975. Also discussed are present status of related standardization activities in areas of command langruages, terminal keyboards, and terminology. Legal implications of standardization are indicated, and establishment of a Federal Task Group for Standardization is proposed to work under the Federal Information Processing Standards Coordinating and Advisory Committee (FIPSCAC).

Key words: Command languages; computers; man-machine systems; networks; system commands; user protocols.

\section{Present Status of User-Terminal Protocol Standandization}

There are many different varieties of user-terminal protocols, differing from each other in detail of information required from a user, and in type of information fed back to the user from the system. These protocols are used with a great number of data bases and these data bases are made accessible through many different services (2). A preliminary study surveyed six systems, a nonrepresentative sample from the standpoint of comprehensive coverage, but sufficient to provide an initial analysis and definition of the problem (3). Under NSF sponsorship a workshop was organized by the National Bureau of Standards (NBS). This workshop provided an opportunity for information exchange and for exploratory discussions of standardization problems, among the thirty five participants. A strawman "candidate standard" document was reviewed by the participants, and the results are reported in a separate document, entitled: A Basis for Standardization of User-Terminal Protocols for Computer Network Access (4). Some of the conclusions of the workshop are summarized in the following paragraphs . 


\subsection{Conclusions of the Workshop}

There was strong consensus that standardization in the area of user-terminal protocols is needed to save user time and to facilitate user access to a variety of systems. There also was consensus that standardization in selected areas is possible, and indeed desirable. As a result of the workshop, the following steps were taken:

a. A revision of the working paper was circulated to participants with a request for comments. The final version is being published (4). This version will serve as the starting point for standardization of user-terminal protocols.

b. Plans are being made to convene a Federal Task Group to identify Federal needs and requirements and possibly develop standards.

c. The National Science Foundation extended the interagency agreement duration for this work to permit smooth transition to an NBS sponsored standardization program.

d. The National Bureau of Standards expressed its desire to continue this work and to furmish technical support and leadership to a Federal Task Group.

\section{Related Standardization Activities}

Several activities are underway which affect possible protocol standards. They are centered around work being conducted by the American National Standards Institute (ANSI) and the projects undertaken under the Federal ADP Standards program. A good summary of these activities appears in reference 5. Work in ANSI is done under the guidance of ANSI Conmittee X3, Computers and Information Processing.

\section{I ANSI Conmittee X3 Computers and Information Processing}

The scope of this comittee encompasses standardization related to systems, computers, equipments, devices, languages, communication characteristics, and physical (non-electric) characteristics of computers and data processing devices, equipments and systems, and media for information processing. The conmittee is responsible for planning, review, and approval of all domestic standardization within its scope and serves, with its subgroups, as technical advisor to its USA member body of the Intermational Organization for Standardization, Technical Comittee 97, Computers and Information Processing (ISO/TC 97) in the area of international standardization. Several key committees are mentioned in the following paragraphs. 


\subsection{ANSI X3 SPARC: Standards Planning and Requirements Comittee}

A central group has been established under X3 which coordinates all standards planning activities. This comittee evaluates the needs for systems standards required to effect the practical and economic interchange of data, files, software and equipment. It also initiates, analyzes, and makes recomendations on new standards projects as input for X3 consideration. The committee audits standards development from a functional and economic view as contrasted with a technical viewpoint, and reviews proposed standards before they are submitted to X3. Final recommendations for a new standard development effort must include an aralysis of the economic motivation of the user and manufacturer, imolementation and transition considerations, applicational utility in the systems environment, analysis of costs of conversion and conformance, and relationships to existing or underdeveloped standards and technical feasibility. SPARC accepts input from all qualified organizations, individuals, and goverment agencies who can contribute to its work.

A special ad hoc group within SPARC has been organized to study the feasibility of operating systems control languages. Parts of a user protocol may deal with operating system commands, and there should be close coupling between any protocol standardization and this group.

\subsection{ANSI X3/SPARC/OCSL (Operating System Control Languages)}

This group investigates the need for and the feasibility of a standard comouter-operating-system control language. This includes control and status aspects of at least interactive, timesharing and batch-processing systems. The cormittee has conducted a survey of langrage functions for control and status reporting offered by major operating and single-language systems and has documented similarities and differences. As of 1971 no agreement had been reached for a proposed standard, the possible desirability of multiple standards and a proposed plan of standardization. The committee work has been dormant for some five months, has been recently (Spring 1975) revised and has formulated a new rork program which will include consideration of elementary user functions performed by operating systems, determination of the feasibility of a universal command language, and determination of the economic impact of such a command langruage. While the work of this groun covers an area very close to that being investigated by the CODASY cormittee on OSCL (see 2.4), approaches differ markedly. The SPARC/OSCL group is primarily concerned with establishment of feasibility and functional "top-down" definition of such a langrage. The CODASYL effort has defined a number of elemental language functions based on a variety of existing languages and is planning to work towards grouping of these functions and towards establishing a "bottom-up" language design procedure. Thus, both efforts hopefully will merge and augment each other. Close liaison is maintained between both groups with that objective in mind. 
2.4 CODASYL/OSCLTG: Conference on Data Systems Languages/Operating Systems Command Language Task Group

The CODASYL effort is subdivided into several standing committees: the executive, planning, systems, progranming languages, and data description langrage committees. The executive committee, limited to 15 members, is responsible for the overall management of the standing comnittees. Several Task Groups report to the appropriate standing committees. The Systems Committee sponsors a Task Group on operating systems cormand languages .

This group was established with the following objectives:

1. Investigate functional requirements for conmunication between the user, the functional programs and the hardware. In present day systems all such communication is normally channeled through the Operating System and the form of cormunication is known as the Operating System Control (or command) language.

2. To determine the functions necessary to define a standard OSCL interface and what problems such a standard interface implies in the building of an operating system.

This group has been meeting since February 1973 and its members represent hardware manufacturers, users and academicians.

Close liaison needs to be maintained by user protocol standardizers with both efforts.

Another related effort designated Committee X3K5 deals with conceptual grouping and documentation of terms and definitions.

\subsection{ANSI Committee X3K5: Terminology and Glossary}

This committee coordinates and advises the other technical committees of $\mathrm{X} 3$ in establishment of definitions required for their proposed standards. It presently is developing a general dictionary for computers and information processing and also supports development of an international vocabulary for computers and information processing.

Both character codes and data elements play an important role in user-terminal protocols and strong efforts are underway in these areas in Comittees X3L2 and X3L8.

\subsection{ANSI Committee X3L2: Character Codes}

Its scope covers standardization of coded character sets, including code representations, recording formats and format indicators, and those characteristics of input/output equipment required to interchange media between systems and equipment. Study projects underway which may impact 
or may be impacted by user protocol standardization are control codes for 8 bit sets, maintenance of the ASCII code (X 3.4-1968), and 8 bit code and code extension procedures.

\subsection{ANSI Comittee X3L8: Representations of Data Elements}

The mission of this comittee is to develop standards for describing the representations of data elements involved in data interchange and for representing data elements of common interest, such as the elements concemed with representations of times, locations, individuals, organizations and materials. The program for proposed standards includes time, time zone and date representations, organization identifiers, representations for political subdivisions, mailing addresses, and point locations.

Another grouping of standardization tasks is related to office machine standardization.

\subsection{ANSI Comittee X4: Office Machines}

One of the main comoonents of a terminal is the keyboard. Standardization of keyboards traditionally falls under the heading of office machines. Technical Comittee X4A9 is concemed with keyboard standardization. Present standards for the ASCII keyboard (X7 and XI4) are under revision at this time (April 1975). User protocols are heavily influenced by certain control characters available on present standard codes and also by the absence of codes required from a standpoint of ease of use and simplicity. New user protocols may well require addition of new codes for certain often used functions such as the system and user signals, help command, etc. Usser protocol standardization must build on existing keyboard standards, but should at the same time inject new requirements into this effort.

\subsection{Relevant International Standards}

Intemational standards have been and are being developed under the auspices of the Intemational Organization for Standardization (ISO). Several existing standards might affect imolementation of user protocols, in the areas of data elements for calendar representation (8), (9) and time of day representation (10).

\section{Federal Infomation Processing Standards}

The Federal Government and especially the National Bureau of Standards, U.S. Department of Comerce, play a leadership role in standards development. Under the ADP Standards Progran authorized by Public Iaw 89-306 (the Brooks Act):

The Secretary of Commerce is authorized... (2) to make appropriate recommendations to the President relating to the establishment of uniform Federal Automated Data Processing Standards. 
Subsequent directives relevant to this program are Executive Onder 11717, and Part 6 of Title 15 of the Code of Federal Regulations. Under the Executive Order the Secretary of Commerce assumed responsibility for all functions relating to establishment of Govermment-wide standards for automatic data processing, previously performed by the Office of Management and Budget, including the function of approving Standards on behalf of the President. Under Part 6 Title 15 of the CFR, the National Bureau of Standards assumes a leadership role in the management of activities within the Federal Government relating to the development, implementation, and maintenance of data standards. (7)

It is recognized that information processing standards are being developed nationally under the auspices of the American National Standards Institute (ANSI) and internationally under the auspices of the Intermational Organization for standards (ISO). It is important that Federal Information Systems be compatible not only with each other but with those of State and Local govermments, the private sector of the economy and those of other nations. Accordingly, standards developed to meet Federal Requirements should to the extent practicable be consistent with corresponding ANSI and ISO Standards.

In order that Federal interests are adequately reflected in such standards, NBS in its standards management role is responsible for assuring Federal participation in their development. Such particioation is also required for considering them as Federal standards in those cases where they meet the requirements of the Federal Government or for initiating independent development actions in cases where ANSI and ISO efforts do not exist, are too slow, or are leading to results which will not satisfy the Government's needs.

Federal Information Processing Standardization efforts are undertaken by task groups sponsored by the Federal Information Processing Standards Coordinating and Advisory Committee (FIPSCAC). These groups operate under procedures established. by the parent committee. Groups of interest are FIPS Task Group 2, Data Terminals and Data Interchange System Requirements; Task Group 3, Character Subsets, Sign Conventions, and Packing Techniques; Task Group 5, Federal Information Processing Vocabulary; Task Group 14, Documentation for Information Processing Systems; and Task Group 15, Computer Systems Security. A proposed standards effort must take into account work being done by these groups in standardization of terminals, character sets, terminology, documentation and security.

\section{Constraints on the Standaindization Process}

In the development of standards for user-terminal protocols, the first consideration must deal with the user need for simple, reliable and effective access protocols. Other important factors to be considered are the possible impact of standardization on a rapidly emenging technology and possible legal implications, which standardization might have in connection with stifling of competition. Wessel(6) summarizes a recent informal Federal Trade Commission opinion given to the American National Standards Institute (ANSI). In this sumnary he outlines factors affecting the standardization process from a lawyer's viewpoint. To quote Wessel (6): 
"The Federal Trade Commission's opinion to ANSI is therefore most enlightening as to the considerations involved, and (as to) what others must consider even more so. It reads (omitting citations): ${ }^{1}$

"1. Standardization. . . programs must not be used as devices for fixing prices or otherwise lessening competition.

2. They must not have the effect of boycotting on excluding competitors.

3. They must not have the effect of withholding on controlling production.

4. Construction or specification standards should not be used except in exceptional circumstances and never when performance standards can be developed.

5. Standards must reflect existing technology and allow for technological innovation.

8. Mernbership in standards groups must be open to all competitors, domestic and foreign.

9. Due process including timely hearings and prompt decisions on claims . . . must be accorded to all interested parties.

10. Unless clearly required by safety considerations, standards must not restrict the kinds, quantities, sizes, styles or qualities of products.

11. Proposed standards must be checked by an independent entity to insure that they are meaningful and relevant.

14. In challenges to standards, the burden of proof regarding reasonableness is upon those who develop and enforce standards.

15. AIl standards must be voluntary."

To quote Wessel again: ". . . standards . . . can be adopted and can be enforced, if approached properly rather than blindly by the well motivated but inadequateiy informed. A careful interdisciplinary effort is essential, participated in by economists, and representatives of the public in addition to computer scientists and lawyers. The principle guiding them should be:

1 The following numbered items are selected quotations from the cited communication. 
STANDARDS: Computer standards, performance guidelines, . . . should be determined by fairly selected and representative public organizations so as to improve performance and encourage maximum reasonable interchange among computer systems and between economic units without unreasonably impeding technological development in restraining competition."

These statements refer to voluntary standards only. Such standards are developed and promulgated by private organizations, under consensus procedures. Some voluntary standards may however become mandatory standards, regulations, or codes when they are adopted and implemented by a regulatory agency, or by agreement or contract between producer and user. Federal Standards are mandatory for the Federal user community and its suppliers. Even so, certain basic points outlined above may be worthy considerations for those concerned with standardization of user-terminal protocols, including the efforts undertaken by the Federal Government.

\section{Proposed Mechanism for Standards Development}

The workshop in October 1974 provided a first basis for reaching consensus that standardization of user-terminal protocols would be desirable and indeed feasible. Further reflection indicates that standardization efforts, in order to be successful, must be based on needs of those who will utilize these protocols. It is felt that a government sponsored standardization group could materially aid in determination of such requirements using well established coordination mechanisms to obtain this information. It is proposed that a Federal Task Group be set up under FIPSCAC sponsorship.

A proposed scope for such a task group is as follows:

Scope: To develop recommendations to the National Bureau of Standards for user protocol standardization that will improve the effectiveness of Federal ADP operations and systems that support the mission requirements of Federal Departments and Agencies.

The following broad areas for tasks provide a basis of departure for further work and for organization of the task group.

1. To identify the requirements and needs of Federal departments and agencies relative to user protocols for computer networks.

2. To survey, document and evaluate existing industry practices regarding user protocols.

3. To assess the rapidly moving technology and to determine its impact on user protocols. 
4. Based on de-facto practices and Federal government requirements, develop user protocol standards. This would include user entry and exit procedures for computer systems and networks, functional definition and specification, formats and codes, sequencing of functions; hardware and software considerations, and user procedures.

5. To maintain and revise user protocol standards so that these are responsive to the continuing needs of govermment users based upon new applications or technological innovations.

6. To serve as the focal point within the Federal Government for obtaining and expressing the needs of govermment users to obtain industry, govermment and developmental activities involved in the development of standards for user protocols. This includes, but is not limited to the American National Standards Institute, and the activities of professional and trade associations.

7. To conduct seminars or symoosia, as appropriate, to inform govermment users of user protocol standards and their application.

One of the first tasks after establishment of the group would be to establish a detailed work program. It is envisioned that as a minimum a one year program would permit obtaining of useful results. The NBS document: A Basis for Standardization of User Protocols for Computer Network Access (4) would serve as a point of departure.

The work program should contain specific tasks, action items, responsibility assigments, and milestones.

Operating procedures for the group will have to be adopted, based on existing practices in other groups, and specific needs of this group.

Participants should bring to bear expertise in engineering, software development, human factors, and sciences dealing with human communications.

A final report by the task group would provide detailed recommendations for standardization supported by analysis of economic impact of standardization, consideration of imolementation and transitional problems, analysis of conversion costs, relationships to existing standards or those under development and technical feasibility.

During this study it has become clear that some standardization can be and should be undertaken now. At the same time many questions have been raised which lead to identification of problem areas which need to be addressed by further research and development work. 


\section{Further Research and Development Required}

While standardization can be initiated based on existing practices and methods, further work is required to establish a sound scientific basis for both description and evaluation of user-terminal protocols.

Such protocols imply complex hardware-software-people interactions, which need to be described in a uniform descriptive language. Such language is required for training, teaching, self-instruction, as well as for maintenance purposes. It is required to communicate "about" userterminal protocols. Such language would include all terms and functions entered by a user and all messages received by a user at a terminal during system operation, both under normal conditions and under abnormal, or error conditions. This would include a totally exhaustive taxonomy of error conditions which would aid him or systems personnel in restoring the normal operating conditions.

In addition, competing user protocols may have to be evaluated for purposes of procurement or acquisition. Evaluation criteria need to be developed dealing with such factors as: ease of learning, ease of use, ease of reception, readability, structural complexity, tradeoff between natural language and symbology and many other similar factors. A great amount of work has been done in the areas of human factors, human engineering, industrial psychology, and applied linguistics. This work needs to be reviewed critically, keeping the user-terminal protocol measurement problem in mind. Relevant theories need to be identified and experiments need to be designed and undertaken. This would require considerable interdisciplinary effort. Results would be an evaluative capability which would provide system criteria for measurement of quality or "goodness" of userterminal protocols.

\section{Conclusions}

This study has provided an opportunity to make an initial survey of the user-terminal interface with a view towards standardization of user-terminal protocols.

There exists a consensus that some standardization in this area is necessary and indeed is feasible.

At the same time there is strong interaction with existing technology in form of keyboard and code impiementations on one hand, and existing software and procedures on the other hand. A great variety of existing keyboard and software implementations must be taken into account. Another strong factor is developing technology. Automation of data entry needs to be:considered to explore the user-terminal interactions required under error or system malfunction conditions. 
Caution must be exercised not to inhibit technological progress by premature standardization.

A Federal Task Group will be established to undertake standardization in a planned and systematic fashion taking into account technological, legal and other constraints outlined in this paper and working towards development of simple, reliable, and generally applicable user-terminal protocols. In addition to standardization which can begin now in selected areas of userterminal protocols, further research and development work ought to be undertaken in two areas, the descriptive protocol methodology and development of system evaluation criteria which will lead to a measurement capability and an ability to quantify protocol quality, in terms of generally applicable factors. 
8. References

1. D. W. Fife, K. Rankin, E. Fong, J. C. Walker, and B. A. Marron A Technical Index of Interactive Information Systems, NBS Technical Note 819, March 1974.

2. B. Marron, E. Fong, and D. Fife, A Mechanized Information Services Catalog, NBS Technical Note 814, February 1974.

3. A. J. Neumann, User Procedures Standardization for Network Access, NBS Technical Note 799, October 1973.

4. A. J. Neumann, A Basis for Standardization of User-Terminal Protocols, NBS Internal Report , In preparation.

5. National Bureau of Standards, Federal Information Processing Standards Index, FIPS PUB 12-2, December 1974.

6. M. R. Wessel, Setting Standards Can be Illegal,Datamation, January 1975, pp. 145-146.

7. National Bureau of Standards, Objectives and Requirements of the Federal Information Processing Standards Program, FIPS PUB 23, February 1973.

8. Writing of Calendar Dates in All-Numeric Form, ISO/R2014, International Organization for Standards.

9. Representation of Ordinal Dates, ISO 2711, International Organization for Standards.

10. Representation of Time of the Day, ISO 3307, Intermational Organization for Standards. 
NBS.114A \{REV. 7-73)

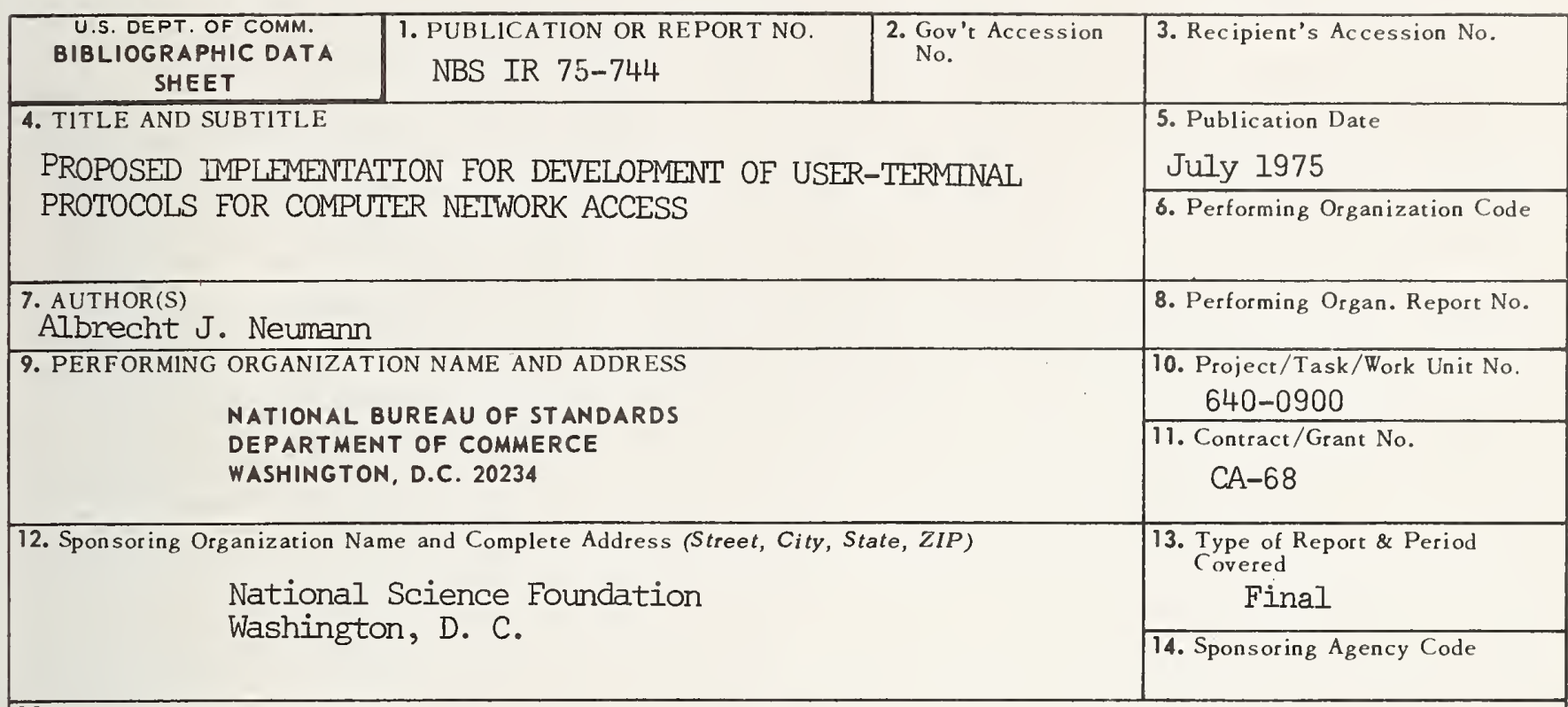

15. SUPPLEMENTARY NOTES

16. ABSTRACT (A 200-word or less factual summary of most significant information. If document includes a significant bibliography or literature survey, mention it here.)

This report summarizes activities undertaken at the National Bureau of Standards in the area of User-Terminal Protocol Standandization with support from the National Science Foundation, during the latter part of 1974 and 1975. Also discussed are present status of related standardization activities in areas of command languages, terminal keyboards, and teminology. Legal implications of standardization are indicated, and establishment of a Federal Task Group for Standardization is proposed to work under the Federal Information Processing Standards Coordinating and Advisory Committee (FIPSCAC).

17. KEY WORDS (six to twelve entries; alphabetical order; capitalize only the first letter of the first key word unless a proper nome; separated by semicolons)

Command languages; computers; man-machine systems; networks; system commands; user protocols.

18. AVAILABILITY [X] Unlimited

For Official Distribution. Do Not Release to NTIS

Order From Sup. of Doc., U.S. Government Printing Office

Washington, D.C. 20402, SD Cat. No. C13

2 Order From National Technical Information Service (NTIS) Springfield, Virginia 22151

\begin{tabular}{|l|c|}
\hline $\begin{array}{l}\text { 19. SECURITY CLASS } \\
\text { (THIS REPURT) } \\
\text { UNCL ASSIFIED }\end{array}$ & 21. NO. OF PAGES \\
\hline $\begin{array}{l}\text { 20. SECURITY CLASS } \\
\text { (THIS PAGE) }\end{array}$ & 22. Price \\
UNCLASSIFIED & $\$ 3.25$ \\
\hline
\end{tabular}





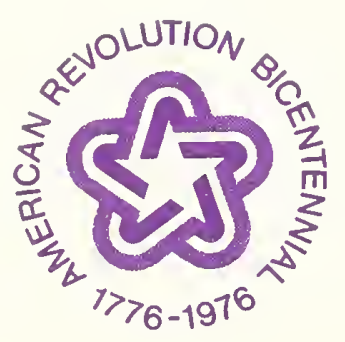

